\title{
PERANCANGAN SEKOLAH INFORMAL UNTUK ANAK ANAK DENGAN PENDEKATAN ARSITEKTUR VISUAL, AUDIOTORIAL, KINESTETIK
}

\author{
Riyan Anggada \\ Program Studi Arsitektur,FTMIPA, Universitas Indraprasta PGRI \\ rynanggada.ra@gmail.com
}

\begin{abstract}
Abstrak
Kota depok adalah sebuah kota yang berada di provisi Jawa Barat, Indonesia. Kota ini terletak diselatan Jakarta, yakni antara Jakarta dan Bogor. Kota Depok terbagi menjadi 11 kecataman dan 63 kelurahan. Kecamatan Cipayung merupakan salah satu kecamatan yang berada di kota depok, dahulunya termasuk dalam kecamatan Pancoran mas namun pada tahun 2009 terjadi sebuah pemekaran dari kecamatan Pancoranmas. Secara pemerintahan mewajibkan setiap kecamatan mempunyai variasi jenis jalur pendidikan untuk mengoptimalkan kualitas pendidikan di masyarakat dan meciptakan sebuah kualitas pendidikan dimasyarakat yang lebih baik. secara data litelatur dan data hasil survei lapangan, pada kecamatan cipayung kota Depok jenis jalur pendidikan masih belum merata. Jenis jalur pendidikan informal di kecamatan cipayung kota depok masih belum ada, jenis jalur pendidikan Nonformal dengan variasi usia terdapat 25 tempat. Dan jenis jalur pendidikan formal terdapat 25 tempat, 15 Sekolah Dasar Swasta dan 10 Sekolah Dasar Negri. Dengan data tersebut bahwa merencanakan sebuah tempat pendidikan Informal di Kecamatan Cipayung Kota Depok ini merupakan sebuah solusi untuk membantu Program Dinas Pendidikan Kota Depok dalam memberikan fasilitas jenis jalur pendidikan di setiap kecamatan yang berada di Kota Depok.
\end{abstract}

Kata-kunci : Perancangan, Sekolah Informal, Arsitektur, Visual, Audiotorial, Kinestetik.

\begin{abstract}
Depok is a city located in West Java province, Indonesia. Located in the south of Jakarta, between Jakarta and Bogor, this city consists of 11 districts and 63 urban communities. Cipayung, one of the districts located in Depok, was once a part of Pancoran Mas district before it became its own district in 2009. Every district was required by the government to optimize the quality of education by providing many variations of educations available in the community. However, from literary study and field study we can infer that the educations level in Cipayung district was still spread unevenly. There were no informal educations available in Cipayung district while formal education only consist of 25 educational institution including 15 private and 10 state operated elementary school. Based on this data, we designed an informal education in Cipayung district in Depok city as a solution to support the program of the Education Board of Depok city in facilitating the education within every district in Depok city.
\end{abstract}

Keywords : Design, Informal Education, Architecture, Visual, Audiotorial, Kinesthetic. 


\section{PENDAHULUAN}

Pendidikan merupakan suatu tuntutan dalam kehidupan tumbuhnya anak-anak yang bermaksud untuk memenuhi kebutuhan kelak dimasa depannya. Pada umumnya pendidikan yang ada di tanah air ini lebih mengarah kepada pendidikan formal. Dalam perkembangan pendidikan khususnya untuk pendidikan anak-anak merupakan hal yang harus diperhatikan lebih utama, karena pendidikan bagi anak-anak sangat berperan penting untuk menentukan masa depan baginya. oleh karena itu pendidikan yang pada umumnya berjalan harus mempunyai pendampingan pendidikan lainnya, guna untuk memperoleh hasil sebuah pendidikan yang lebih baik.

Dewasa ini permasalahan pendidikan yang ada pada pendidikan untuk anak-anak lebih cenderung kepada pendidikan formalnya saja. Akan tetapi pendidikan seperti pengembangan mental dan motorik seorang anak agar dapat memacu kreativitas dan cara berfikirnya cenderung menipis. fenomena mendasar tentang minimnya pendidikan informal untuk anak dapat dilihat dari berbagai faktor, mulai dari faktor keluarga, lingkungan dan kepada penyelenggara pendidikann informal tersebut. Peranan pendidikan informal sejatinya memberikan arahakan untuk anak agar dapat terhindar dari berbagai macam kegiatankegiatan negatif yang merugikan anak tersebut. Sebuah survei menyatakan bahwa perbandingan pendidikan informal dan pendidikan formal mempunyai presentase $80 \%$ dan $20 \%$. Hal ini menggambarkan pendidikan informal masih sangat minim dilingkungan masyarakat, pendidikan informal merupakan sebuah pendidikan pendamping yang berguna untuk mengoptimalkan kecerdasan mental, fisik serta cara berfikir dan bersosialisasi serta mengajarkan anak menjadi anak yang mandiri.
Gaya belajar seorang anak dapat dikatagorikan menjadi tiga, pertama gaya belajar dengan menggunakan metode visual (penglihatan) yakni dengan memberikan bacaan untuk dipelajari ataupun dipresentasikan dengan bentuk gambar dan tulisan. Kedua menggunakan metode auditorial (pendengaran) yakni dengan membacakan sebuah cerita atau menjelaskan sesuatu secara verbal. Ketiga dengan menggunakan metode Kinestetik (gerakan) yakni dengan bersentuhan secara langsung dengan objek yang dipelajari atau secara peraktik langsung.metode metode tersebut dapat dikembangkan untuk mengusung pendidikan informal dan sejatihnya pendidikan informal lebih mengutamakan keaktifan seorang anak agar dapat bersentuhan langsung dengan media objek pembelajaran dan memberikan anak-anak bergerak bebas untuk dapat mengekpresikan dirinya. Oleh karena itu cara belajar visual, audotorial, kinestetik lebih diutamakan di bidang pendidikan informal.

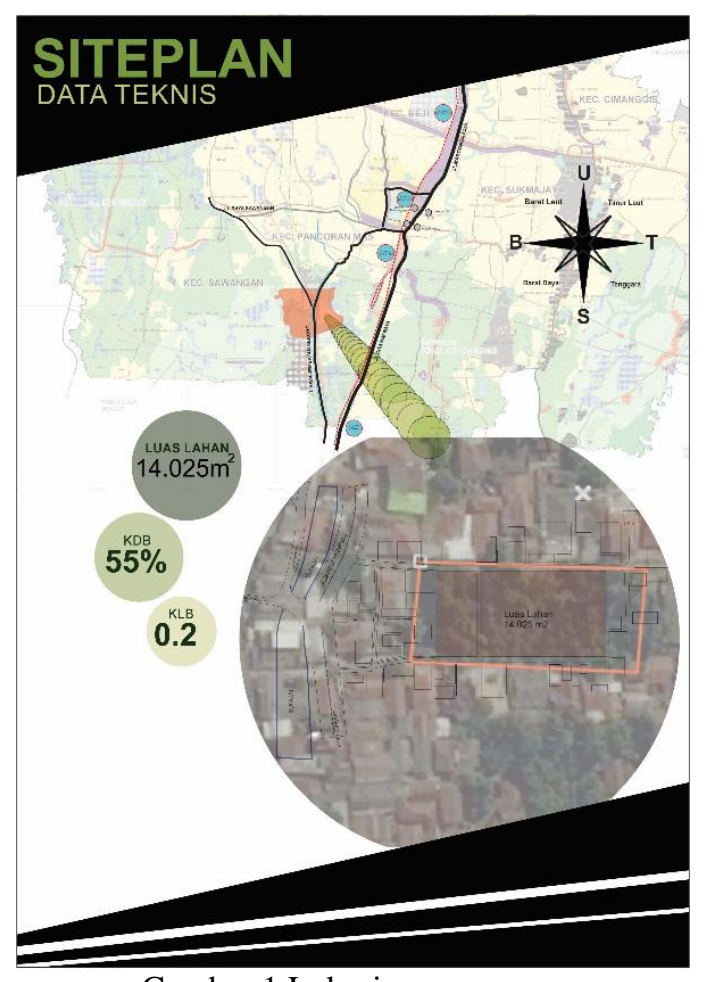

Gambar 1.Lokasi perencanaan 
Pemilihan lokasi tapak proyek pada alamat Jl.Jembatan Serong, Kecamatan Cipayung, Kelurahan Cipayung yang masuk dalam (RW) Rukun Wilayah 02 ini mendukung kegiatan perencanaan yang dilakukan, karena disamping membantu program pemerintah, perancangan bangunan pendidikan informal ini dapat membantu menambah fasilitas untuk lingkup rukun warga ini sebagai sarana belajar pendidikan informal

Berdasarkan perkembangan penggunaan lahan saat ini, kecamatan Cipayung telah berkembang sesuai dengan arahan Rencana Pemanfaatan Ruang yakni sebagai pemukiman kepadatan bangunan. Dengan sesuai rencana yang ditetapkan oleh pemerintah kota Depok lingkungan tapak menjadi sebuah pemukiman yang sesuai dengan fungsi dengan beberapa fasilitas terbangunan yang sudah ada seperti Mushola, Majlis Taklim, Masjid dan sekolah dengan masyarakat pada umumnya yang mayoritas pemeluk agama Islam.

Keadaan lingkungan tapak yang jauh dari kebisingan dan polusi udara membuat masyarakat pada lingkungan meraasakan kenyamanan dan masih banyaknya pepohonan besar sehingga membuat lokasi tapak menjadi menarik dan asri. Tidak hanya banyak pepohonan akan tetapi fasilitas sosial warga pun cukup terjangkau dari lokasi tapak. Mulai dari tempat ibadah, saranan sekolah sampai kepada saranan komersil dan saranan kesehatan. Hal tersebut akan membuat lokasi tapak menjadi lebih optimal karena di dukung dari beberapa macam kebutuhan baik yang mendukung secara langsung pendidikan maupun secara tidak langsung.

\section{METODE PERANCANGAN}

Sebuah pendekatan yang dilakukan untuk mendapatkan metode pendekatan perancangan ini berlandaskan dari isu perancangan yakni sebuah perancangan banguna pendidikan informal untuk anakanak. Proses untuk mendapatakan metode pendekatan perancangan ini dimulai dari memahami tentang apa arti dari bangunan pendidikan tersebut dan tentang sistem jenis jalur pendidikan. Karena hal inilah yang menjadi sebuah pola pikir mendasar dalam mendesain dan berarsitektur.

Metode Pendekatan mengadopsi dari sebuah pemikiran dari James $\boldsymbol{J}$ Gibson dengan istilah Affordance, "presepsi yang mencerminkan pengembangan pemikiran dan penekanan pada makna melalui intraksi antara presepsi dan tindakan dengan pendekatan ekologi lingkungan". Ketika di kaitkan kepada metode pendekatan perancangan arsitektur prinsip Affordance, mempunyai makna dalam melakukan pendekatan perancangan, yakni dalam memulai sesuatu baik dalam proses analisis dan pengumpulan data teknis harus di lengkapi dengan data pengatar atau sebuah teori arahan agar sebuah presepsi atau sebuah pemikiran dalam melakukan pendekatan mempunyai gagasan yang kuat dan baik. Ekologi lingkungan digunakan untuk memperkuat sentuhan metode dalam merancangan, memperhatikan segalam macam unsur unsur yang ada pada kondisi lapangan baik dari segi potensi dan hambatan. Sehingga intraksi antara mahluk hidup maupun mahkluk hidup dengan lingkungan mempunyai keharmonisan bersama dalam satu kawasan atau sebuah tempat.

\section{HASIL DAN PEMBAHASAN}

Fungsi dari bangunan ini merupakan sebuah wadah atau tempat belajar untuk anak anak usia 6-11 tahun dengan jalur pendidikan informal. Bangunan yang dirancang ini sedikit berbeda dengan bangunan pendidikan pada umumnya karena dilatar belakangi 
bangunan pendidikan informal. Dengan dasar pendidikan informal yang lebih dominan kegiatan belajar mengajar bersifat intraktif dan berhubungan langsung dengan media dan objek pelajaran, sehingga ruang-ruang yang dihadirkan bersifat terbuka, mempunyai lebih dari satu fungsi, dan menghadirkan nuansa belajar yang aktif.

Dengna fungsi vital sebagai tempat pendidikan yang digunakan untuk kalangan anak-anak, bentukan dari bangunan menghadirkan penyesuaian kondisi lingkungan dan kondisi pengguna bangunan. Lebih menghadirkan aspek keamanan, kenyamanan dan keharmonisan antara bangunan dan lingkungan alam sekitar.

\section{Analisis Produk}

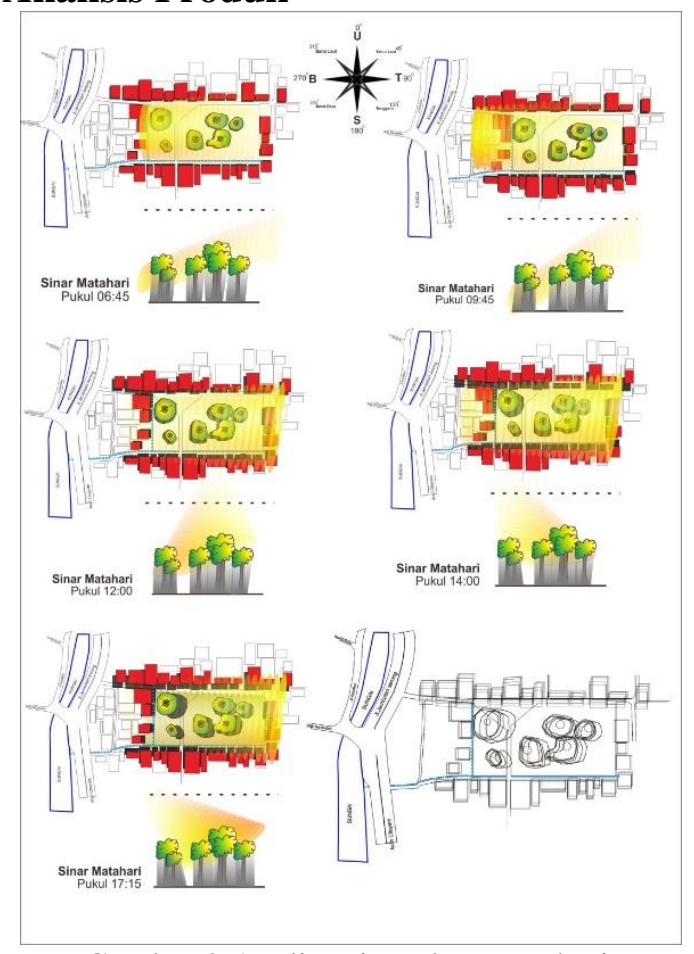

Gambar 2.Analisa sinar data matahari

Bayangan sinar matahari didapat mulai dari pukul 06:45 sampai pukul 17:15 menciptakan sebuah bentuk yang dapat dimanfaatkan untuk membentuk ruang ruang di bawah sinar bayanganya atau sebagai pewujudan bentuk masa bangunan. Sehingga analisa yang dilaku- kan mendapatkan sebuah tatak letak masa bangunan dan penzoningan secara lingkup macro. Dan secara rinci memberikan peluang untuk bermian dengan bukaan-bukaan.

Penzoningan atau pembagian area pada perancangan ini di bagi menjadi 2 jenis, yaitu Penzoningan Makro, dan Penzoningan Mikro, lingkupan penzoningan di bagi menjadi 2 bagian agar penempatan area atau pembagian area bisa dilakukan secara terperinci dan lebih teratur. Adapun penjelasan dari 2 jenis penzoningan tersebut.

Penzoningan Makro

Meliputi kawasan siteplan, tata letak bangunan dan kawasan batas lingkup antara pengguna dan pengurus. Seperti contoh, lahan parkir, taman, panggung pertunjukan outdor, tempat menunggu, tempat bermain.

\section{Penzoningan Mikro}

Meliputi ruang ruang yang ada di dalam bangunan dan area area khusu atau umum yang berkaitan dengan fungsi banguan. Seperti contoh, ruang public, ruang semi public, semi privat, privat, dan servis.

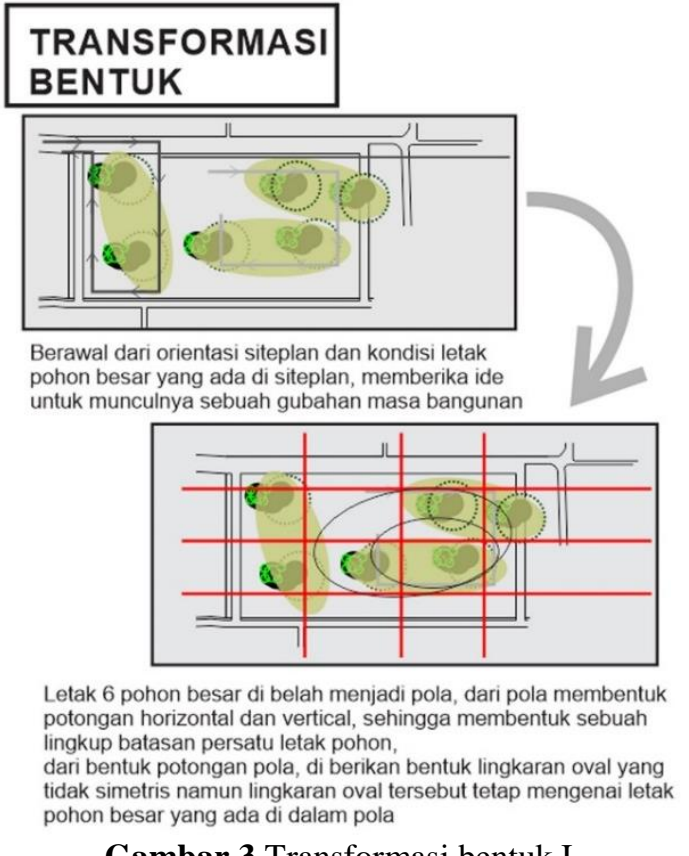

Gambar 3.Transformasi bentuk I 


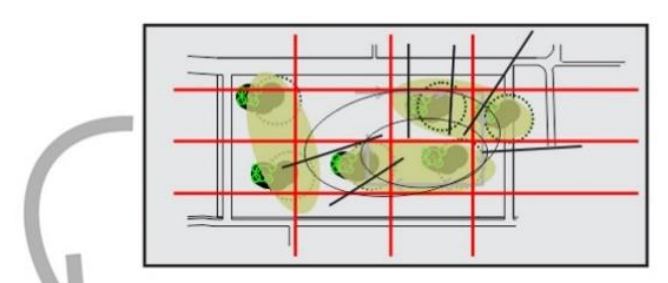

Bentuk lingkaran oval yang berada di dalam pola potong pada siteplan, di potong berdasarkan letak 4 pohon yang yang berada di area tengan site.

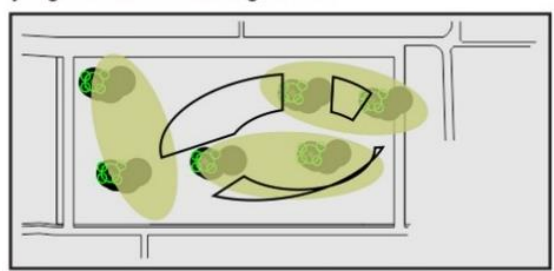

Bentuk lingkaran oval yang terpotong berdasarkan letak 4 pohon membentuk sebuah bentuk dasar geometri dasar bangunan

Gambar 4.Transformasi bentuk II

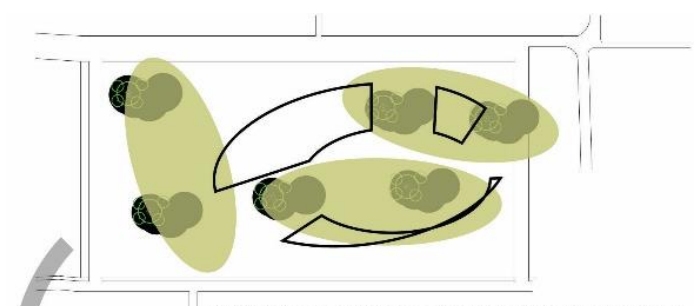

Bentuk geometri yang dihasilkan dari beberapa proses. di oleh menjadi sebuah masa bangunan

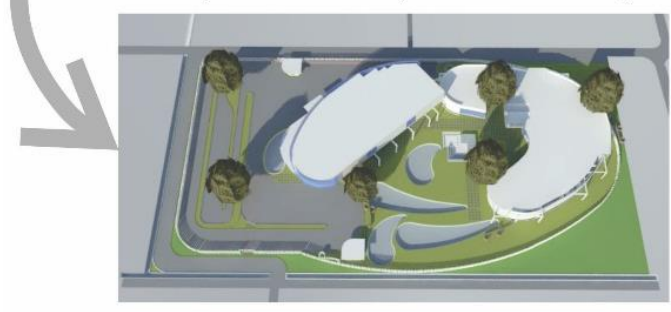

Masa bangunan yang di dapat dari awalan sebuah proses transformasi bentuk, dan berbagai penyesuaian mulai dari bentuk ruang, dimensi, komposisi,proposi, sehingga menciptakan sebuah bentuk seperti ini.

Gambar 5.Transformasi bentuk III

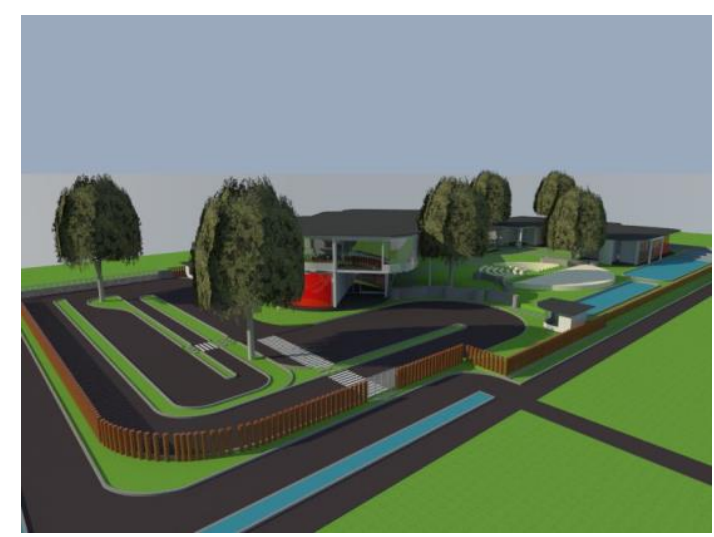

Gambar 6.3D Siteplan I

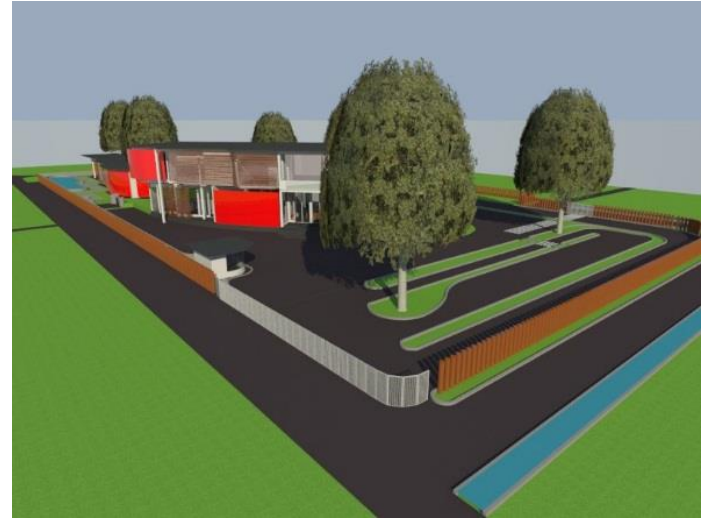

Gambar 6.3D Siteplan II

\section{SIMPULAN}

Pendidikan Informal merupakan salah satu jenis jalur pendidikan yang di akui oleh pemerintah dan di tulis di dalam perundang-undangan. Dan sejatihnya pendidikan informal tidak mempunyai kurikulum seperti pendidikan formal dan nonformal akan tetapi pentingnya sebuah pendidikan tidak bisa diukur dari kurikumnya saja. Melainkan dari apa yang dihasilkan melalu proses pendidikan tersebut. Pendidikan informal memang lebih banyak mengajarkan sesuatu yang tidak tertulis di dalam buku namun sering kali tertera di dalam kehidupan seharihari. Meskipun masih banyak yang beranggapan pendidikan informal hanya sebuah pendidikan yang sama dengan pendidikan yang didapat di sekolah. Akan tetapi pada kenyataannya tidak seperti itu. Pendidikan informal dapat memberikan manfaat yang baik untuk anak-anak terutama untuk keahlian bersosial dan berintraksi dengan orang lain atau lingkungan sekitar.

Six Tree School ini merupakan sebuah wadah atau tempat belajar dengan jenis jalur pendidikan informal. yang berada di kota depok. Kecamatan cipayung. Keberadaan banguanan pendidikan ini untuk memberikan kemudahan bagi masyarakat guna mendapatkan pendidikan informal dan memberikan ruang untuk anak agar bisa beraktivitas dengan bimbingan dan arahan yang baik. 
Six Tree School di rancang dengan pendekatan arsitektur VAK (Visual, Audiotorial, Kinestetik) VAK merupakan sebuah gaya belajar turunan yang di kembangkan oleh prof.Howard Gatnerd seorang psikologi. Prinsip-prinsip VAK itulah yang diambil dan dikembangkan di dalam proses berarsitektur. Dalam berarsitektur dan mengembangkan prinsip VAK dibantu dengan teori Affordance oleh James J Gibson seorang psikologi anak. Sehingga prinsip dan pemahaman teori serta penuntutan dari fungsi banguan dapat tercapai semua.

\section{DAFTAR PUSTAKA}

Adiyono. (2006). Menghitung Konstruksi Beton. Depok. Griya Kreasi

Butet, M.. (2013). Sakola Rimba. Jakarta. PT. Kompas Media Nusantara.

Er nst, N.uefert. (1996a). Data Arsitek Jilid I, Jakarta. Erlangga

(1996b). Data Arsitek Jilid II, Jakarta. Erlangga
Francis D K, C. (2000). Arsitektur Bentuk, Ruang dan Tatanan Edisi ketiga. Jakarta. Erlangga

Kementrial Kebudayaan Dan Pariwisata, (2004). Standar Toilet Nasional. Jakarta.Nirwono, J. dan Iwan, I. (2011). RTH 30\%! Resolusi (kota) Hijau. Jakarta. PT Gramedia

Nirwono. J. (2013). Gerakan Kota Hijau. Jakarta. PT Gramedia

Rustam, H., dan Eka, S.R. (2006). Komunikasi Grafis Arsitektur dan lanskep. Jakarta. PT Bumi Askara.

Sutrisno. R. (1984). Bentuk Struktur Bangunan Dalam Arsitektur Modern. Jakarta. PT Gramedia.

Undang-Undang Republik Indonesia No. 20/2003 tentang Sistem Pendidikan Nasional.

White T. E.. (1985). Analisa Tapak. Bandung. Intermatra. 